\title{
Belphégor
}

\section{Di Gregorio, Luca: Wilderness et Western. L'Ouest fictionnel chez Gustave Aimard et Emilio Salgari.}

\section{François-Xavier Eygun}

\section{(2) OpenEdition}

1 Journals

\section{Electronic version}

URL: http://journals.openedition.org/belphegor/714

DOI: 10.4000/belphegor.714

ISSN: 1499-7185

Publisher

LPCM

\section{Electronic reference}

François-Xavier Eygun, « Di Gregorio, Luca: Wilderness et Western. L'Ouest fictionnel chez Gustave Aimard et Emilio Salgari. », Belphégor [Online], 14 | 2016, Online since 16 July 2016, connection on 24 September 2020. URL : http://journals.openedition.org/belphegor/714 ; DOI : https://doi.org/10.4000/ belphegor.714

This text was automatically generated on 24 September 2020 .

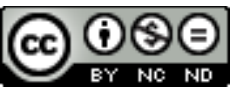

Belphégor est mis à disposition selon les termes de la Licence Creative Commons Attribution - Pas d'Utilisation Commerciale - Pas de Modification 4.0 International. 


\title{
Di Gregorio, Luca: Wilderness et Western. L'Ouest fictionnel chez Gustave Aimard et Emilio Salgari.
}

\author{
François-Xavier Eygun
}

\section{REFERENCES}

Di Gregorio, Luca: Wilderness et Western. L'Ouest fictionnel chez Gustave Aimard et Emilio Salgari, Liège : Presses Universitaires de Liège, Série Littératures, 2014. 246p.

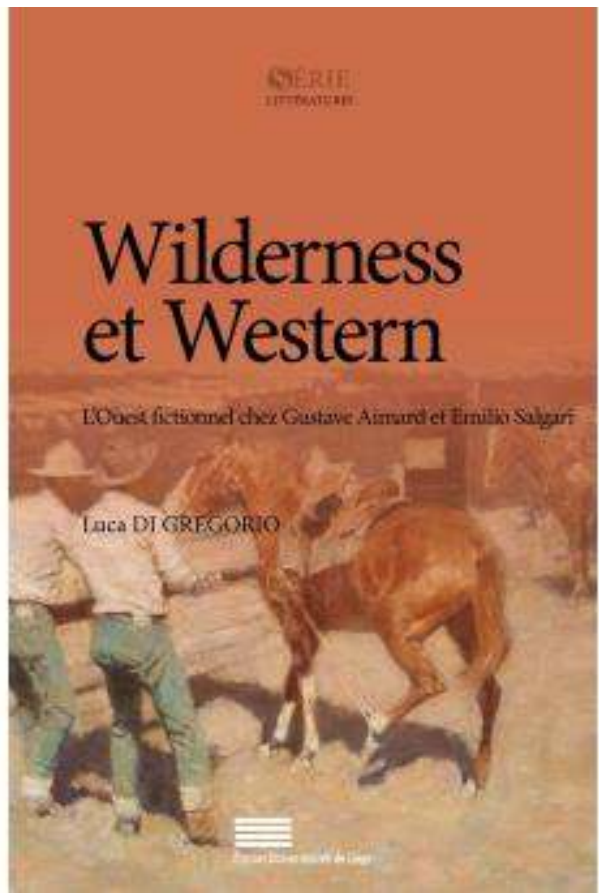


1 Cet ouvrage a pour origine un mémoire de Master qui fut couronné par le prix de la BiLA (Bibliothèque des Littératures d'Aventures) de Chaudfontaine en 2011, et est paru à la fin de l'année 2014 en Belgique. C'est donc un ouvrage académique et parfois un peu scolaire mais qui se lit facilement une fois que le lecteur a fait fi du jargon et des préciosités littéraires. Pour qui a fréquenté - ou non - Gustave Aimard et Emilio Salgari, l'intérêt de ce livre est énorme car il étudie dans le contexte de l'ouest américain l'évolution d'un courant western, divisé ici entre wilderness et western. La démonstration est brillante et fait preuve non seulement d'une vaste culture littéraire ce qui est la moindre des choses - mais appréhende aussi clairement deux imaginaires bien distincts qui composent ce que l'on appelle le western aujourd'hui et qui est une construction non seulement historique mais aussi esthétique.

2 Cet ouvrage assez dense, d'environ 250 pages, est accompagné d'illustrations, d'un épilogue et d'annexes en plus d'une bibliographie exhaustive et d'un index. C'est donc un outil très complet qui offre une démonstration approfondie du monde western par et à travers surtout la littérature. Le corpus se divise en quatre parties ou séquences intitulées " Deux imaginaires de l'ouest », "Gustave Aimard et le wilderness », " De wilderness en western (1870-1900) » et « Far West et tragédie chez Salgari ».

3 Les deux concepts de wilderness et western correspondent à « deux états axiomatiques » (p.11), dont le premier va chercher ses sources dans un ouest américain considéré comme sauvage - dans le sens positif du XVIII siècle littéraire et philosophique -, alors que l'autre, plus tardif, correspond à la conquête de l'ouest vécue par un peuple qui en a fait un mythe national. Les deux premières séquences, consacrées au premier concept, le wilderness, sont principalement axées autour de quelques romans de Gustave Aimard - auteur dont la carrière littéraire couvre les années 1854-1883 - romans qui s'articulent autour de conceptions imaginaires et esthétiques héritées du siècle des Lumières et du romantisme.

4 La troisième séquence, allant en gros de 1870 à 1900, voit progressivement se développer le concept de western, qui se nourrit d'une concrétisation sur le terrain de la conquête de l'ouest et de la ruée vers l'or qui en fut une des motivations principales. Ce phénomène de bouleversement démographique va instaurer un autre imaginaire qui servira de mythe national non plus à des Européens en mal de romans d'aventures, mais beaucoup plus à des Américains (à travers par exemple les dime novels) qui vont s'approprier un espace nouveau, et même l'exporter en Europe avec par exemple les spectacles du Buffalo Bill Wild West Show dans les années 1880.

5 La quatrième séquence, celle qui traite du "Far West et de la tragédie chez Salgari », cherche à inscrire cet immense auteur italien de romans d'aventures dans un imaginaire western, mais comme le souligne l'auteur (p.159) il s'agit plus d'une rupture de l'imaginaire, et en cela ce chapitre est moins convaincant et donne l'impression d'une argumentation hétéroclite plus difficile à suivre pour un lecteur qui serait peut être moins au courant de l'œuvre de Salgari.

6 Finalement ce compte rendu limite un peu, et nécessairement, la portée de l'ouvrage de Luca di Gregorio, qui offre bien plus que ce résumé ne peut le suggérer. Cela reste un ouvrage brillant, malgré ses imperfections, sur un épisode mythique qui continue de façonner la culture et l'imaginaire non seulement des Américains, mais aussi de tous ceux qui s’inspirent et/ou dépendent de la culture nord-américaine. 


\section{AUTHOR}

\section{FRANÇOIS-XAVIER EYGUN}

Modern Languages Department - Mount Saint Vincent University. 